\title{
Analysis and Design of Fuel Cell Fed Modified SEPIC Converter for REGS
}

\author{
Dolly Murodia ${ }^{1}$, Ashok Kumar Sharma ${ }^{2}$, Priyanka Nehra ${ }^{3}$ \\ M. Tech Scholar, Department of Electrical Engineering, Rajasthan Technical University, Kota, India ${ }^{1}$ \\ Associate Professor, Department of Electrical Engineering, Rajasthan Technical University, Kota, India ${ }^{2}$ \\ M. Tech Scholar, Department of Electrical Engineering, Rajasthan Technical University, Kota, India ${ }^{3}$
}

\begin{abstract}
Fuel cells have conceivable to mask a key execution in the motility of future. This study substitutes a new blueprint topology for fuel cell power generation in passable to surplus the eminently reliable relevance power. Owing to the fuel cell has lesser voltage at output it demands to be boosted by a step-up dc to dc converters for the idealization of later inverter. The paper substitutes different topography of dc to dc converters which have individual advantages for fuel cell power generation. Afterward, modified SEPIC converter is used for the generation of fuel cell power which will substantiate the reflect of using modified SEPIC in preference of other dc to dc converters.
\end{abstract}

Keywords: Fuel-Cell, DC to DC Converters, SEPIC, Grid- Coupled Inverter

\section{INTRODUCTION}

Fuel cells technology is considered to be most promising energy generation device due to its high efficiency, low emission, low operating noise, environment friendly [1], [2]. There are various types of fuel cells are present from which PEMFC is considered as quite efficient as compared to others with the application such as portable power, transportation etc. Implementing power electronics applications in fuel cell systems is a solution that allows fuel cell technology to be used in any application. The low temperature fuel cell is the PEMFC displayed in Fig. 1.

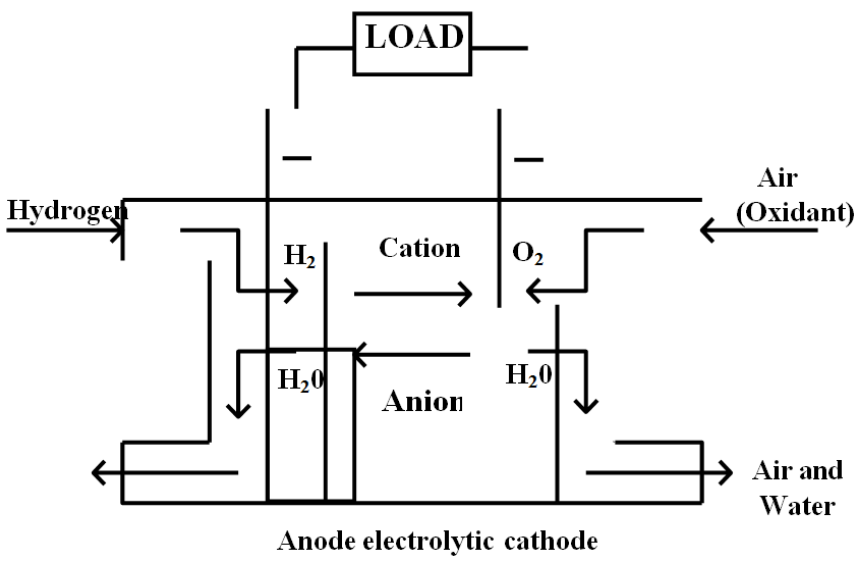

Fig.1 Operation of PEM fuel cell

During operation, the hydrogen, methanol in the anode chamber is oxidized while the $\mathrm{O} 2$ in the cathode is reduced. The exchange membrane is present which cannot reciprocate quickly when load changes.

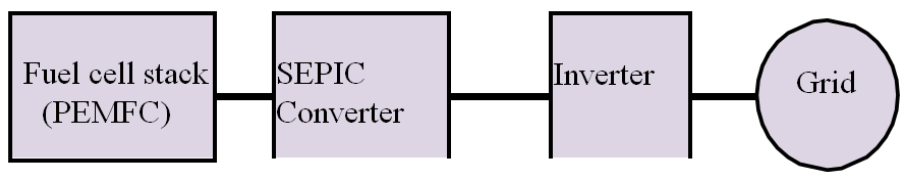

Fig. 2 Block diagram of proposed system

Therefore, it is compulsory to use a converter to compensate the variation in load. A step-up converter is used to boost the voltage to high level(200V). The efficiency of this converter is approximately $40 \%$ [3]. Half- bridge, full-bridge, push-pull converters are used to boost the lower voltage of the FC to the recognized level [4], [5]. The turn ratios (like 


\section{International Journal of Innovative Research in Electrical, Electronics, Instrumentation and Control Engineering}

Vol. 7, Issue 6, June 2019

1:20) of isolated transformer are large enough. Hence, large leakage inductances cause low efficiency, duty cycle loss which result in difficulty to handle the dc-dc converter [6]. In the power converters, a Single-Ended Primary Inductance Converter (SEPIC) is adopted having features of the buck-boost mode, low current pulsation, no polarity inversion and wide voltage range at input.

\section{TOPOGRAPHY OF DCCONVERTERS}

Distinct DC converters are procurable that can hike or decline the eminence of the DC voltage. Inherently, a power MOSFET \& a diode is used, however, other semiconductor switches such as IGBT, BJT or thyristors are also used for dish out the maximal proficiency \& constancy.

A.

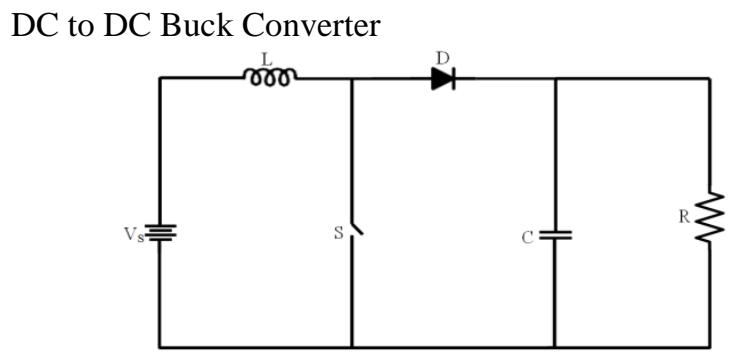

(a)

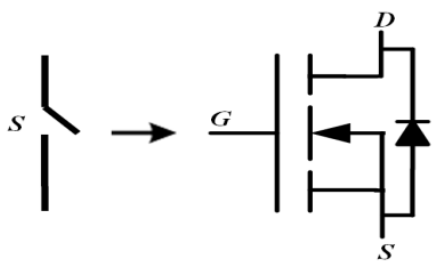

(b)

Fig.3 Topography of Buck-Boost DC to DC converter

The buck converter is used to reduce the DC voltage consisting the topology with low number of components and low control complexity. As compared to traditional buck converter, a DC to DC buck converter proved that the voltage across the switch is $50 \%$ lesser as compared with 2 level ZVS.

\section{B. DC to DC Boost Converter}

A boost converter includes a switch, an inductor, a diode and a controller for switch. It can be operated in two modesCCM \& DCM which is characterized by current waveform of the inductor. In CCM-current of inductor is greater than zero while in DCM current of inductor falls to zero after each switching cycle. The boost converter includes characteristics such as continuous input current, low input ripple current which is favorable for fuel cell application.

C.

$$
\text { DC to DC Buck-Boost Converter }
$$

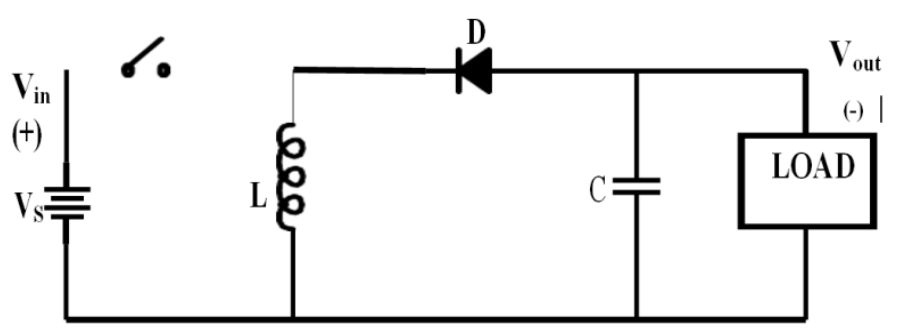

Fig. 4 Buck-Boost DC to DC converter

The basic circuit of a buck-boost converter consists of a switching element, inductor, diode, and capacitor. The difference between a buck-boost and a boost converter is the arrangement of the switching element placed before the inductor, as displayed in Fig.4. This topography can work with greater than, equal to and less than the input voltage and hence, suitable for portable applications. These three conditions with different duty cycle can be operated. When the duty cycle is lesser than 0.5 , the converter operates in buck mode while larger than 0.5 , the converter operates in boost mode. For equal voltage, the duty cycle should be equals to 0.5 .

Chen.[7] proposed a buck-boost converter with PWM technique consisting two switches that can operated as boost or buck depending on the input and output conditions.

Hwang.et.al [8] focused on average current controlled low voltage buck-boost converter. This topography can deduce cost, size, system complexibility.

\section{DC to DC CUK Converter}

The Cuk converter includes input and output ports with an inductor in series. The main advantage of Cuk converter is that the current ripples is lesser and the efficiency is good. It can also reduce EMI generation. 


\section{International Journal of Innovative Research in Electrical, Electronics, Instrumentation and Control Engineering}

Vol. 7, Issue 6, June 2019

\section{E. DC to DC SEPIC Converter}

Single-ended primary inductance converter is a dc to dc converter topography which provides a regulated output voltage with no polarity inversion. It has features like step-up and step-down the voltage by changing duty cycle of the switch, wide voltage range at input. It has advantages which is applied to generation system of fuel cell such as-

a) An Inductor is present at input terminal which can decline the input current pulses and can overcome the drawback of electric-current pulses of FC to maximal the accuracy of the system

b) Operate under boost or buck cases.

\section{OPERATING PRINCIPLE OF BASIC SEPIC CONVERTER}

However, this is not considered for losses due to diode drop $\mathrm{Vd}$. Therefore, equations may be given as

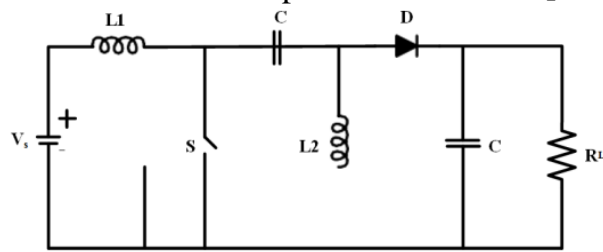

Fig.5 Basic SEPIC topology

In Fig.5, basic SEPIC topology is displayed where $\mathrm{V}_{\mathrm{S}}$ is the input voltage, $\mathrm{S}$ is the switch consist of MOSFET, L1 and L2 are the inductors, $\mathrm{D}$ is a diode, $\mathrm{C}$ are capacitor and $\mathrm{R} 1$ is the load output. The maximal $\mathrm{D}$ (Duty cycle) will obtained when the voltage in input is at minimum value. The minimal D will obtain when the voltage in input is at maximum value. The larger the inductors, the circuit is more efficient. However, large value of inductors is quite expensive and have large internal resistance which further decrease the converter efficiency. Hence, for better design of circuit, L can be calculated as

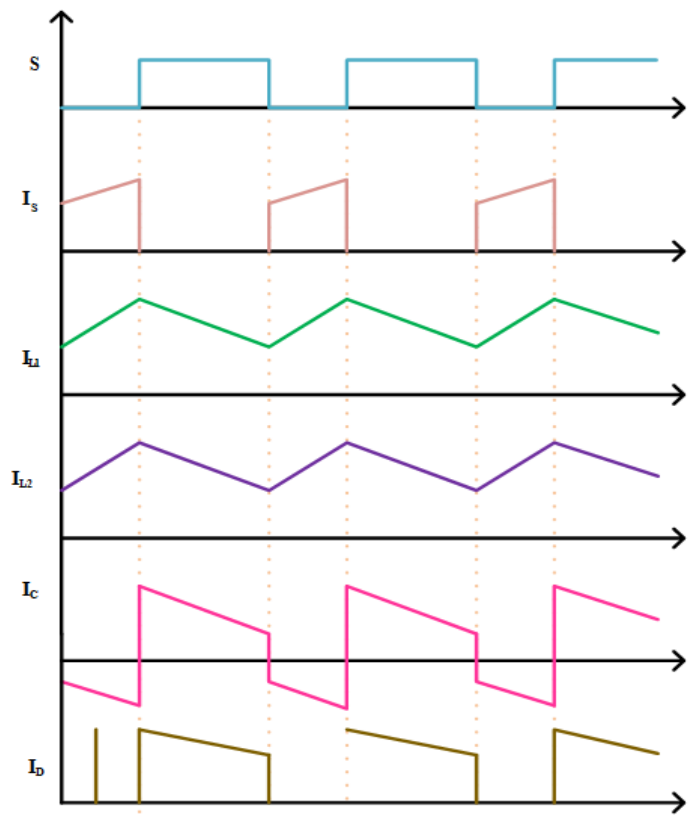

Fig.6 Operation waveform of SEPIC converter

When the switch is OFF, the L (inductor) output goes through the D to the Rl load and the capacitor become charged. When the percentage of time becomes greater, the switch is OFF, the output will be greater. It is because inductors charge for a longer which result in high voltage.[10] The SEPIC converter buck or boost the voltage primarily based on duty cycle $\mathrm{D}$ and the elements present in the circuit. The output of SEPIC is given by

$$
V_{0}=\frac{D \underline{V_{S}}}{1-D}
$$




\section{International Journal of Innovative Research in Electrical, Electronics, Instrumentation and Control Engineering}

Vol. 7, Issue 6, June 2019

However, this is not considered for losses due to diode drop $\mathrm{V}_{\mathrm{d}}$. Therefore, equations may be given as

$$
\mathrm{V}_{\mathbf{0}}+\mathrm{V}_{\mathrm{D}}=\frac{\mathrm{D}+\mathrm{V}_{\mathrm{S}}}{1-\mathrm{D}}
$$

Further, simplified as

$$
D=\frac{V+V}{V_{S}} \frac{D}{V_{0}+V_{D}}
$$

The maximal D (Duty cycle) will obtained when the voltage in input is at minimum value. The minimal D will obtain when the voltage in input is at maximum value. The larger the inductors, the circuit is more efficient. However, large value of inductors is quite expensive and have large internal resistance which further decrease the converter efficiency. Hence, for better design of circuit, $\mathrm{L}$ can be calculated as

$$
L=\frac{V_{S(\min )}\left(D_{\text {max }}\right)}{\Delta \mathbf{i}_{\mathbf{0}(\max )} \mathbf{f}_{\mathbf{s}}}
$$

Due to interesting operating characteristic of SEPIC converter for static gains, the topology is not suitable for high power factor at input side. Therefore, a voltage multiplier technique was straightened in order to expand the static gain of single- phase boost dc to dc converter.

\section{MODIFIED SEPIC CONVERTER TOPOLOGY}

The converter with the modification in basic SEPIC topology is composed of diode DN and capacitor CN displayed in Fig.5. The operating conditions are changed. The $\mathrm{CN}$ is charged with the boost converter output voltage. Therefore, the voltage across L2 during ON time of switch is higher as compared to basic SEPIC topology which results in higher static gain. In the modified SEPIC, the polarity of capacitor C is inverted give some theoretical analysis [9]. For higher efficiency, the power circuit can be merged with regenerative snubber.

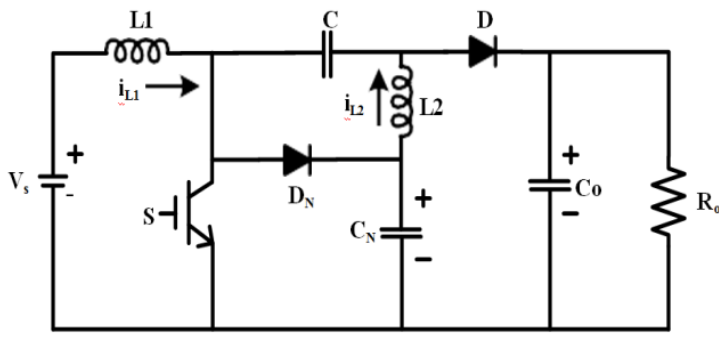

Fig.7 Modified SEPIC converter

The modified SEPIC converter is designed in CCM and consist of two stages.

I. I Stage- The $\mathrm{S}$ is turned OFF and the stored energy in $\mathrm{L} 1$ is transferred to the $\mathrm{C}$ output and D output, also to the newly added $\mathrm{CN}$ through the $\mathrm{DN}$. Hence, the capacitor voltage $\mathrm{CN}$ is equal to switch voltage.

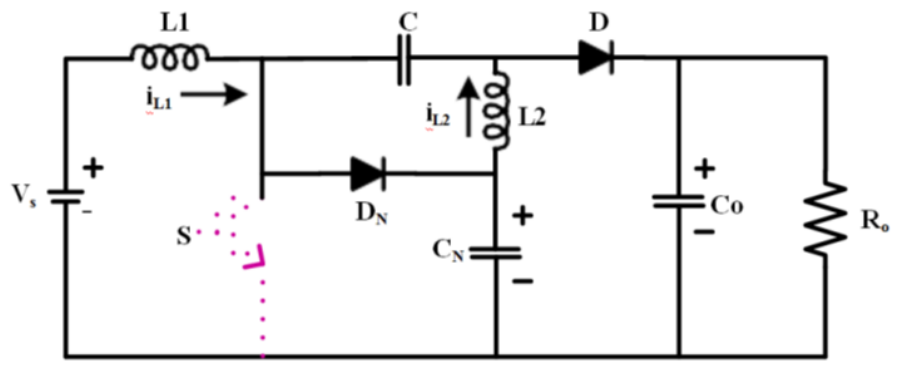

Fig.8 First operation

II Stage- The S is turned $\mathrm{ON}$ and the DN and D are blocked and the L1 and L2 stores energy. The voltage VC and VCN is applied to L2 while the input voltage is to $\mathrm{L} 1$. The voltage $\mathrm{VCN}$ becomes higher. 
International Journal of Innovative Research in Electrical, Electronics, Instrumentation and Control Engineering

Vol. 7, Issue 6, June 2019

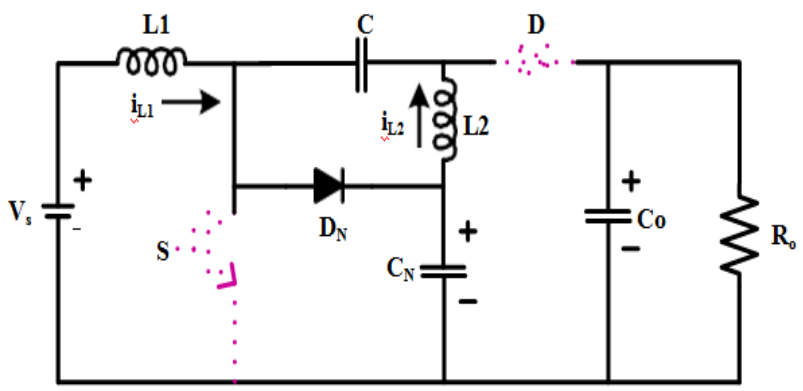

Fig.9 Second operation

The static gain of new modified SEPIC is given by-

$$
\begin{aligned}
& \mathbf{V}_{\mathbf{S}} \mathbf{t}_{\mathbf{O}}=\left(\mathbf{V}_{\mathbf{C N}_{\mathbf{N}}}-\mathbf{V}_{\mathbf{S}}\right) \mathbf{t}_{\text {OFF }} \\
& \mathbf{V}_{\mathbf{S}} \mathbf{D}=\mathbf{V}_{\mathbf{C N}}-\mathbf{V}_{\mathbf{S}}(\mathbf{1}-\mathbf{D})
\end{aligned}
$$

Therefore, $\mathrm{CN}$ i.e capacitor voltage is given by

$$
\frac{\mathrm{V}_{\mathrm{C}_{\mathrm{N}}}}{\mathrm{V}_{\mathrm{S}}}=\frac{\mathbf{1}}{\mathbf{1 - D}}
$$

During $\mathrm{S}$ off, the diodes $\mathrm{DN}$ and $\mathrm{D}$ are in state of conduction and the relation between them is given by

$$
\mathrm{V}_{0}=\mathrm{V}_{\mathrm{CS}}+\mathrm{V}_{\mathrm{CN}}
$$

During steady state condition, the value of average voltage across L2 is zero and the relation is given by

$$
\begin{array}{r}
V_{C S}-V_{C_{N}} t_{0 N}=V_{0}-V_{C_{N}} t_{\text {OFF }} \\
V_{C S}-V_{C_{N}} D=V_{0}-V_{C_{N}} 1-D
\end{array}
$$

Hence the static gain of the modified converter is given by

$$
\begin{aligned}
& V_{C S}=V_{0}-V_{C_{N}} \\
& V_{\underline{o}}=\frac{1+D}{1-D} \\
& V_{\mathbf{s}}
\end{aligned}
$$

\section{COMPARISION BETWEEN BASIC SEPIC AND MODIFIED SEPIC}

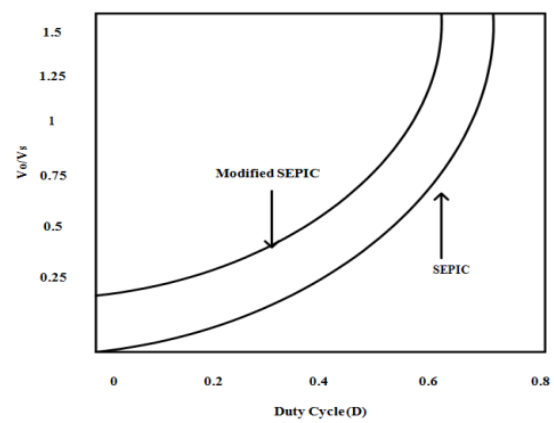

Fig.10 Static gain of basic SEPIC and modified SEPIC converter

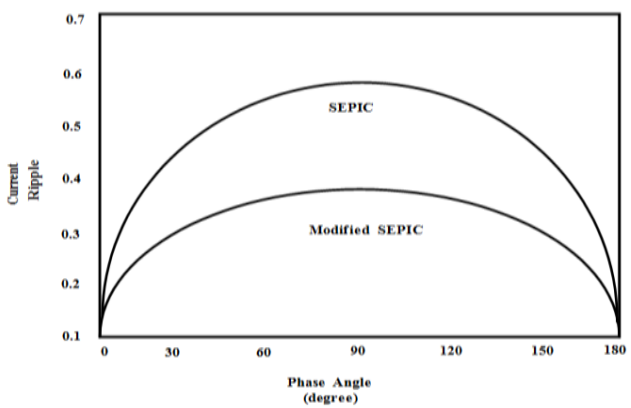

Fig.11 Comparison of input ripple current between basic SEPIC and Modified SEPIC 
Vol. 7, Issue 6, June 2019

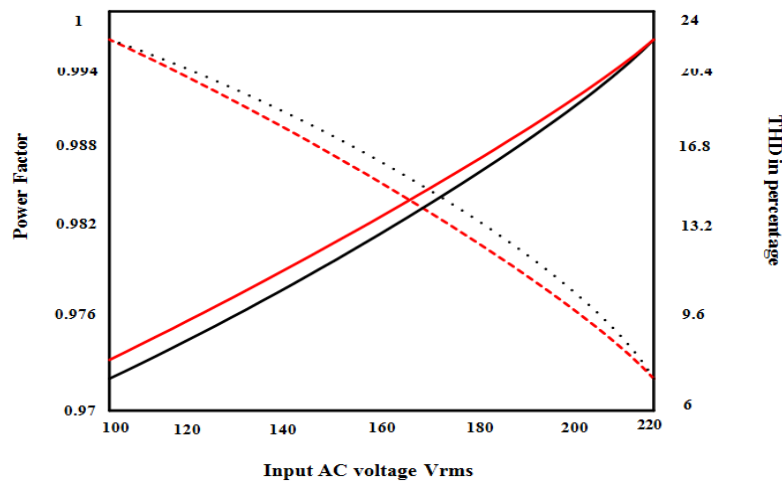

Fig.12 Comparison between pf and THD with respect to input voltage

The Minimal output $(\mathrm{D}=0)$ is double of the input voltage. Therefore, it is not used for input application [9] as displayed in Fig.10. Higher the static gain results in improvement with low voltage in input. Maximum input ripple current is known as input inductance value. Both converters have same input voltage, the determination of current ripple is same for all converter as displayed in Fig.11. The modified SEPIC converter improves pf as compared to basic SEPIC as displayed in fig. 12.

\section{SINGLE-PHASE FULL-BRIDGE INVERTER}

DC-AC conversion uses a full bridge inverter topology to give fixed frequency as well as voltage of the single-phase power. The circuit is displayed in Fig.13. For low harmonics and stable voltage, the SPWM technique is adopted.

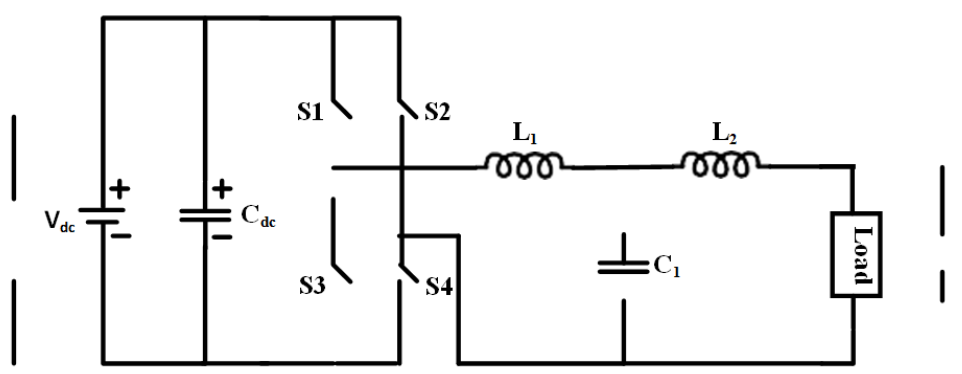

Fig.13 Single phase full bridge inverter

VII. SIMULATION MODEL AND RESULTS
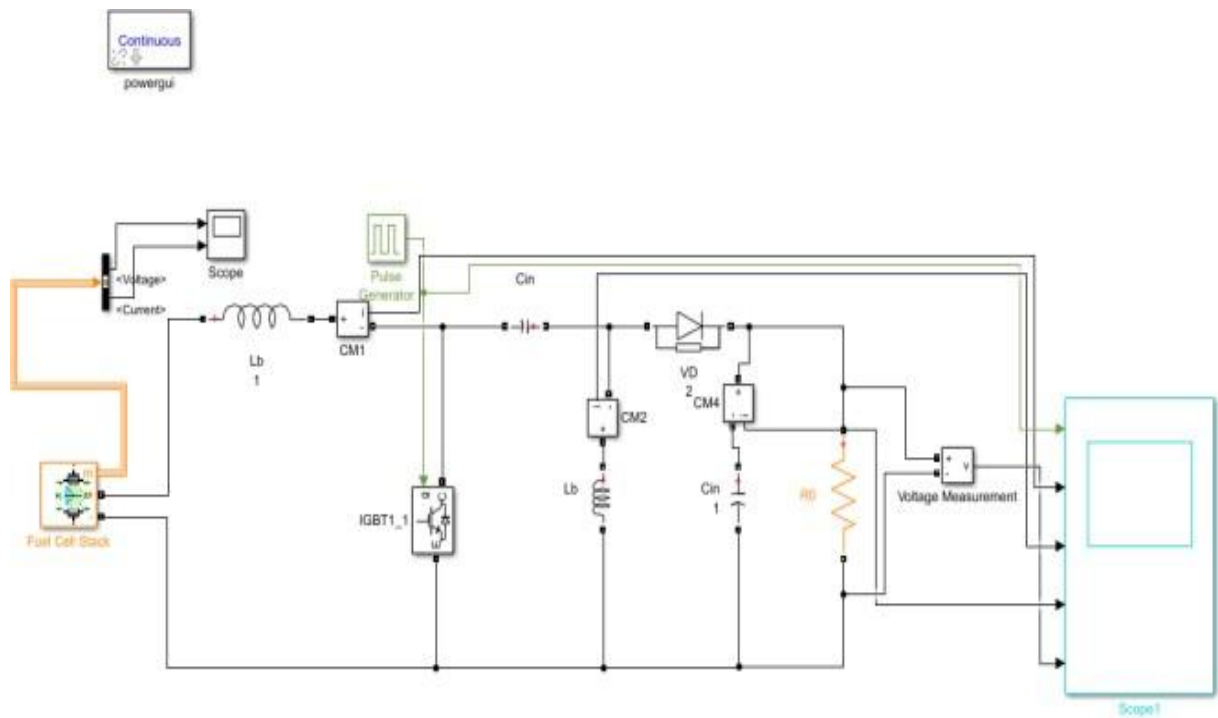

Fig.14 Simulation model of basic SEPIC 
International Journal of Innovative Research in Electrical, Electronics, Instrumentation and Control Engineering

Vol. 7, Issue 6, June 2019

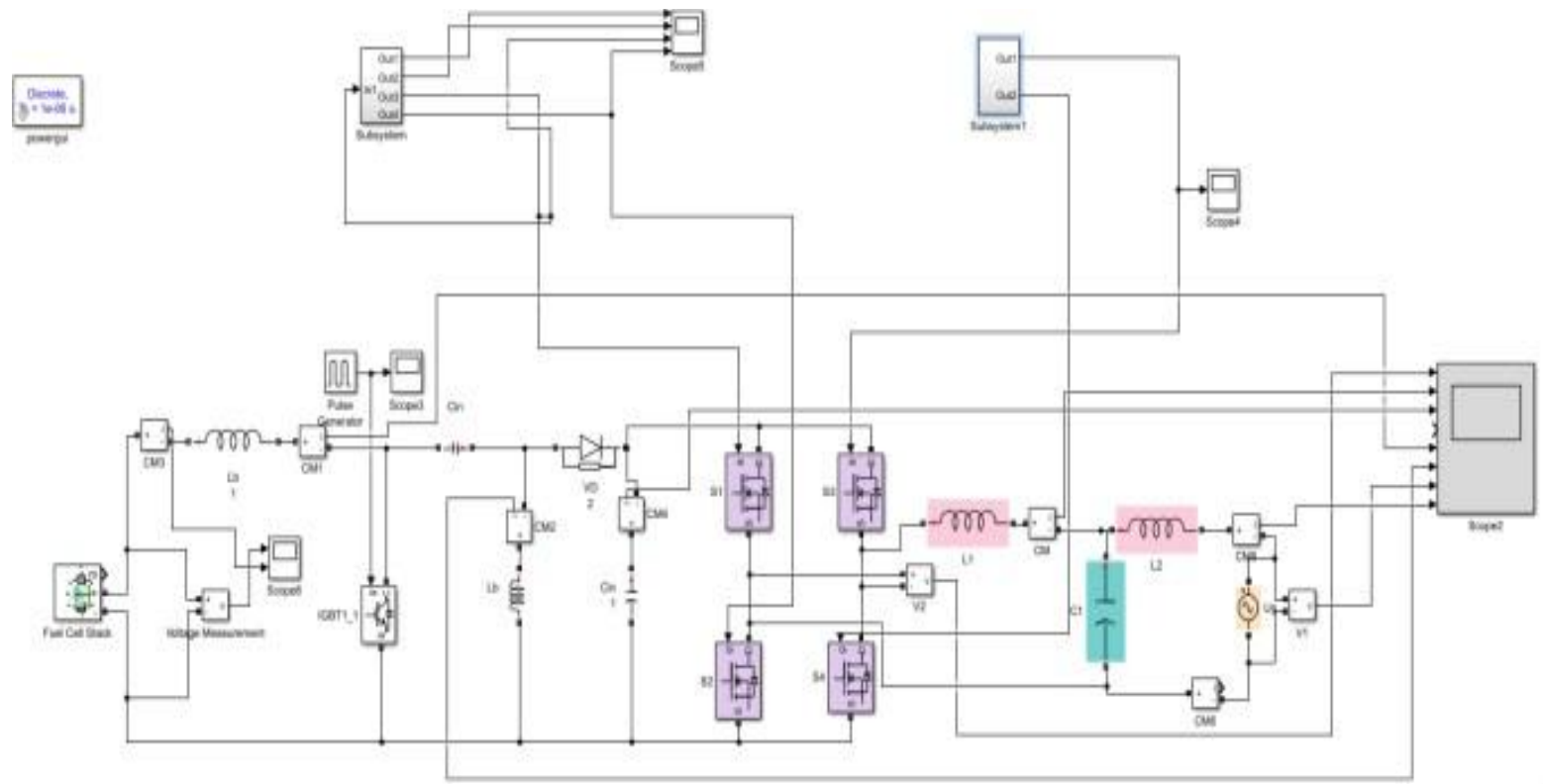

Fig.15 Simulation model of modified SEPIC with full bridge inverter
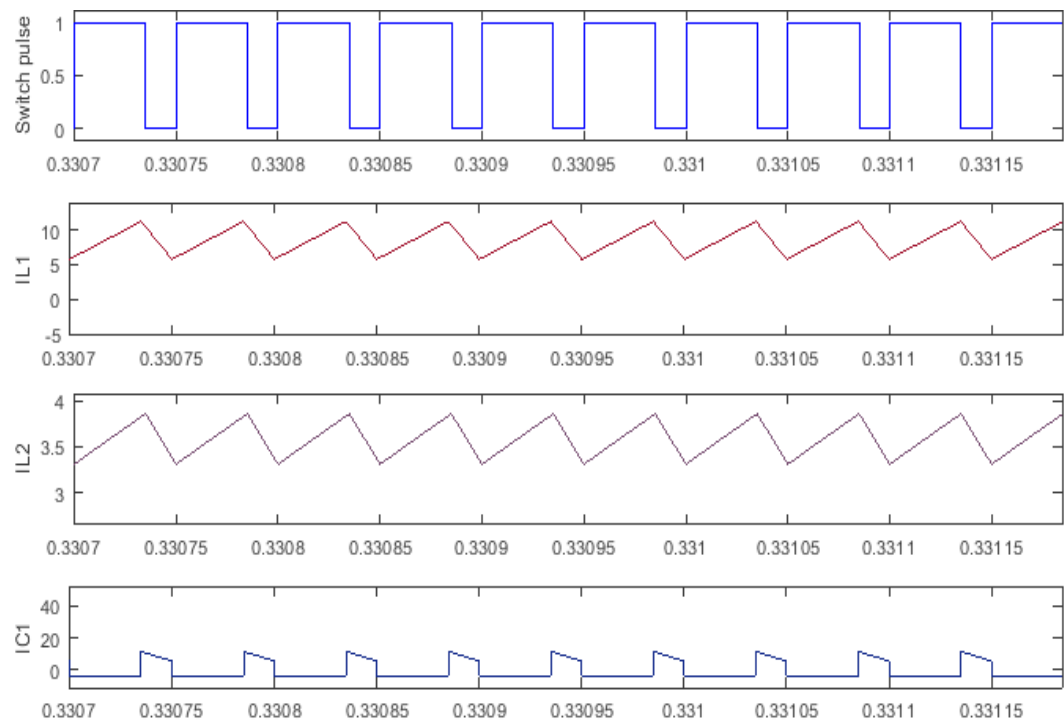

(a)

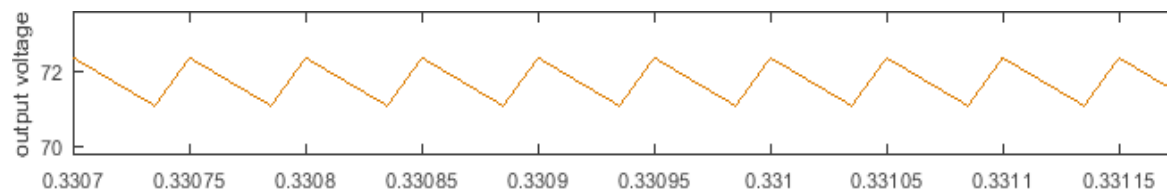

(b)

Fig.16 Simulation results of the projected inverter

The open loop simulation models of basic SEPIC and modified SEPIC with full bridge inverter are displayed in fig.14 and fig.15. The waveforms of simulation models are displayed in fig.16(a), where switch pulse (on-off time) of MOSFET, current across iL1 and iL2 and current across IC1 capacitor is displayed. Fig.16 (b) displayed voltage in output. 


\section{IJIREEICE \\ International Journal of Innovative Research in Electrical, Electronics, Instrumentation and Control Engineering}

Vol. 7, Issue 6, June 2019

\section{CONCLUSION}

This paper presents that the fc (PEMFC) is used with $1.24 \mathrm{~kW}-24 \mathrm{Vdc}$ for power generation system. Various dc to dc converters are discussed from which SEPIC is taken with the advantages. Comparison between basic SEPIC and modified SEPIC is done displayed by the basic graphs where the duty ratio, THD, voltage gain, input current ripple of modified SEPIC is quite better. The modified SEPIC converter system configuration is used with full bridge inverter topology to meet up the required level. All the specification for designing of FC based SEPIC was designed to provide high gain regulated dc voltage to the system. It is proved that the modified SEPIC converter have better performance for fuel cell energy production system.

\section{REFERENCES}

[1]. R. Sharma and H. Gao, "Low Cost High Efficiency DC-DC Converter for Fuel Cell Powered Auxiliary Power Unit of a Heavy Vehicle," IEEE Trans. Power Electronics, Vol. 21, No. 3, pp. 587-591, May.2006.

[2]. Todorovic, M.H.; Palma, L.; Enjeti, P.N, "Design of a Wide Input Range DC-DC Converter With a Robust Power Control Scheme Suitable for Fuel Cell Power Conversion," IEEE Trans. Ind. Electronics, Vol. 55, No. 3, pp. 1247-1255, Mar. 2008.

[3]. Sung-Sae Lee; Seong-Wook Choi; Gun-Woo Moon, "High-Efficiency Active-Clamp Forward Converter With Transient Current Build-Up (TCB) ZVS Technique,” IEEE Trans. Ind. Electron., Vol. 54, No. 1, pp. 310-318, Feb. 2007.

[4]. Y.-K. Lo, T.-S. Kao, and J.-Y. Lin, “Analysis and design of an interleaved active-clamping forward converter," IEEE Trans. Ind. Electronics, Vol. 54, No. 4, pp. 2323-2332, Aug. 2007.

[5]. EG\&G Technical Services, Inc. Science Applications International Corporation, Fuel Cell Handbook, 7th ed. Morgantown, WV: U.S. Dept. of Energy, Office of Fossil Energy, National Energy Technol- ogy Laboratory, Nov. 2004.

[6]. S.Inoue \& H. Akagi, "A bidirectioanl isolated dc-dc converter as a core circuit of the next-generation medium-voltage power conversion system," IEEE Trans. Power Electronics, Vol. 22, No. 2, pp. 535-542, Mar. 2007

[7]. J. Chen, D. Maksimović, and R. Erickson, "Buck-boost PWM converters having two independently controlled switches," in Proceedings of the IEEE 32nd Annual Power Electronics Specialists Conference, pp. 736- 741, June 2001.

[8]. B.-H. Hwang, B.-N. Sheen, J.-J. Chen, Y.-S. Hwang,and C.-C. Yu, "A low-voltage positive buck-boost converter using average-currentcontrolled techniques,"in Proceedings of the IEEE International Symposium on Circuits and Systems (ISCAS '12), pp. 2255-2258, Seoul,Republic of Korea, May 2012.

[9]. P. F. de Melo, R. Gules, E. F. R. Romaneli and R. C. Annunziato, "A Modified SEPIC Converter for High-Power-Factor Rectifier and Universal Input Voltage Applications," in IEEE Transactions on Power Electronics, vol. 25, no. 2, pp. 310-321, Feb. 2010

[10]. L. Huber, Y. Jang and M. M. Jovanovic, "Performance Evaluation of Bridgeless PFC Boost Rectifiers," in IEEE Transactions on Power Electronics, vol. 23, no. 3, pp. 1381-1390, May 2008 